\title{
Levosimendan in Acute Decompensated Heart Failure: Systematic Review and Meta-Analysis
}

\author{
Rodrigo Antonini Ribeiro1, Luis Eduardo Paim Rohde 2,3,4, Carisi Anne Polanczyk 2,3,4 \\ Programa de Pós-Graduação em Epidemiologia - Universidade Federal do Rio Grande do Sul'; Serviço de Cardiologia - Hospital de Clínicas \\ de Porto Alegre²; Faculdade de Medicina - Universidade Federal do Rio Grande do Sul; Instituto para Avaliação de Tecnologia em Saúde - \\ $\mathrm{CNPq} q^{4}$, Porto Alegre, RS - Brazil
}

\begin{abstract}
Background: Congestive heart failure (CHF) is a rather prevalent condition with a high mortality rate. Levosimendan is one among the new drugs that have been tested for its management.

Objective: To undertake a systematic review and meta-analysis of the morbidity and mortality reduction associated with levosimendan in the treatment of CHF.

Methods: A bibliographic search was conducted in the Medline database for all randomized controlled trials (RCTs) that assessed the use of levosimendan in CHF. The outcomes were death from all causes, length of hospital stay, and hospital readmission for CHF. All RCTs with outcomes of interest were included. Methodological quality criteria, such as blinding and confidentiality of the list of allocation, were evaluated in sensitivity analysis. The main calculation was done with random effects.
\end{abstract}

Results: Of the 179 articles identified, 48 were RCTs, 19 of them with outcomes of interest. In the comparison with placebo ( 7 trials, 1,652 patients), the relative risk (RR) for overall death was 0.87 (95\% confidence interval [CI]: 0.65 to 1.18). In comparison with dobutamine (10 trials, 2,067 patients), the RR was 0.87 (95\% $\mathrm{Cl}: 0.75-1.02)$. Three studies had data on length of stay, in which levosimendan showed a decrease of 2.27 and 2.30 days compared to placebo and dobutamine, respectively ( $p<0.05$ for both). No article presented data on readmission alone.

Conclusion: The evidence available so far has shown no benefit in terms of mortality in association with the use of levosimendan, which only showed a small benefit in the time of hospitalization. (Arq Bras Cardiol 2010; 95(2): 230-237)

Key words: Heart failure; levosimendan; drugs, investigational; meta-analysis.

\section{Introduction}

Heart failure (HF) is a common condition, and congestive heart failure $(\mathrm{CHF})$ is the third general cause and the first cardiovascular cause of hospitalization in Brazil. In 2006, according to DATASUS data, there were approximately 300,000 hospitalizations for HF in public hospitals in Brazil, with a direct spending of more than $\mathrm{R} \$ 220$ million reals and a mortality rate of almost $8 \%{ }^{1}$.

During the course of the disease, especially in severe cases, there are periods of acute heart failure decompensation, with high risk of complications, arrhythmias and death. The management of patients presenting CHF and low output signals is controversial, and there has been no consensus, even among experts, on which would be the best treatment strategy ${ }^{2}$. Drugs that improve the contractile performance of the heart (positive inotropic agents) are often used in such

Mailing address: Rodrigo Antonini Ribeiro •

Avenida Alegrete 373/402 - Petrópolis - 90460-100 - Porto Alegre, RS - Brazil E-mail: rodrigoantonini@yahoo.com.br

Manuscript received March 10, 2009; revised manuscript received October 08, 2009, accepted December 17, 2009. a clinical context, although several experts question the use of this class of agents in HF. This questioning is based on the fact that, historically, almost all of the positive inotropic agents studied in large randomized controlled trials (RCTs) increased the risk of death, presumably due to arrhythmic causes ${ }^{3,4}$.

Levosimendan is a calcium sensitizing drug that is commercially available in Brazil since 2002. By the sensitizing action of troponin $\mathrm{C}$ to calcium, levosimendan has the potential to improve cardiac contractility in systole without impairing relaxation in diastole. This drug may also have a vasodilator action, which may result in improved cardiac output without increasing myocardial oxygen demand. An active metabolite of the drug (OR1896) maintains the clinical response between 7 and 9 days after continuous intravenous infusion for 24 hours ${ }^{5,6}$.

Several clinical trials have been conducted to evaluate levosimendan compared with inotropic agents - especially with dobutamine - and with placebo. So far, individual data from controlled trials comparing levosimendan with placebo have failed to demonstrate that the use of continuous or intermittent dobutamine improves the survival of patients with decompensated HF. In this study, our objective was 
to summarize the available evidence through systematic review and meta-analysis calculation, evaluating the impact of levosimendan on the clinically relevant outcomes of total mortality, readmission for $\mathrm{CHF}$, and hospitalization time. As a secondary objective, the adverse effects associated with this medication were also reviewed.

\section{Methods}

Initially, we conducted a search for systematic reviews and meta-analyses in the Medline, Cochrane, and SumSearch databases. Later on, a search for clinical trials was conducted, using the Medline bibliographic database, accessed via PubMed. The use of Levosimendan in patients with heart failure was defined as the scope of the analysis. The outcomes targeted in the search, considered as clinically relevant, were as follows:

1. Death from all causes

2. Time of hospitalization

3. Readmission to hospital for heart failure

In the search strategy, rather than selecting randomized controlled trials (RCTs) with PubMed filters, we used a list of words previously validated for searching this type of study, which was more sensitive than PubMed filters ${ }^{7}$. In the search strategy, to avoid missing studies that might have had a description of these outcomes only in the full-text article, and not in the abstract, we did not include words related to the outcomes of interest. The search strategy used was as follows:

Levosimendan AND heart failure AND ((randomized controlled trial[pt] OR controlled clinical trial[pt] $O R$ randomized controlled trials $[\mathrm{mh}] \mathrm{OR}$ random allocation $[\mathrm{mh}]$ OR double-blind method [mh] OR single-blind method [mh] OR clinical trial[pt] OR clinical trials[mh] OR ("clinical trial"[tw]) OR ((singl*[tw] OR doubl*[tw] OR trebl*[tw] OR tripl*[tw]) AND (mask*[tw] OR blind*[tw])) OR ("latin square"[tw]) OR placebos[mh] OR placebo*[tw] OR random*[tw] OR research design[mh:noexp] OR comparative study[mh] OR evaluation studies[mh] OR follow-up studies[mh] OR prospective studies[mh] OR cross-over studies[mh] OR control*[tw] OR prospectiv*[tw] OR volunteer*[tw]) NOT (animal[mh] NOT human $[m h])$ )

After conducting the search, which was set to end by 07/07/2009, we evaluated all abstracts found. Studies described as having the design of a clinical trial comparing the use of levosimendan versus placebo or another active treatment were selected for full text search. We also searched for abstracts that could lead to unpublished studies, such as conference highlights. The references of the studies included were searched for other possible relevant studies.

The method chosen to accomplish the compilation of the available evidence was a meta-analysis. We opted for a pragmatic criterion for inclusion, in which all randomized controlled trials with the pre-specified outcomes were included, and methodological quality criteria were used in subsequent sensitivity analyses. According to current recommendations, the following methodological criteria were deemed as most relevant:

1. Description of sample size calculation;
2. Analysis by intention to treat (intention to treat - ITT);

3. Description of allocation concealment;

4. Use of blinding.

Studies that did not describe whether the analysis was by "intention to treat" were considered as not meeting this criterion. The absence of an explicit description of the allocation concealment - which could include terms such as central randomization, Internet randomization, randomization by telephone, or a clear statement confirming the allocation concealment - also failed to satisfy this criterion. With regard to blinding, both studies described as open (open label) and studies with no description of blinding were considered as not blind.

For its ease of interpretation, the measure of association chosen was the relative risk (RR). The calculation method used was the DerSimonian-Laird random effects method. To assess the heterogeneity between studies, we used the test of inconsistency $\left(I^{2}\right)$, with values below $25 \%$ considered as having little heterogeneity ${ }^{8}$.

To better assess the robustness of the results, several sensitivity analyses were performed. First, we changed the inclusion criteria of the studies according to their methodological characteristics, as described above. In these analyses, the meta-analysis calculations were remade, excluding studies that did not meet certain quality criteria. Moreover, the calculations of the main results (ie, with all studies included) have been redone using the fixed effects method, and we used odds ratio calculation (odds ratio - OR) instead of RR, both by fixed effects and random calculation. Funnel analysis (funnel plot) was used to evaluate the impact of publication bias. The analyses were conducted in Review Manager, version 4.2.10.

\section{Results}

In the search for systematic reviews, we found only one study evaluating levosimendan in CHF, with data updated up to June $2007^{9}$. This study found an OR of 0.83 [95\% confidence interval $(\mathrm{Cl})$ : 0.62 to 1.10 ] for death associated with levosimendan compared to placebo ( 6 studies, $\mathrm{n}=1,578$ ) and 0.75 (95\% Cl: 0.61-0.92) compared with dobutamine (8 studies, $\mathrm{n}=1,979)$. A comparison of dobutamine versus placebo was also performed, showing a significant increase in mortality $(\mathrm{OR}=1.82,95 \% \mathrm{Cl}: 1.06-3.12)$. Other outcomes aimed at in our study were not included in this review. All studies of this systematic review, except for the study conducted by Morelli ${ }^{10}$, were included in this review. The reason for the exclusion of Morelli's study was the type of patients evaluated (septic shock), which differed from the other studies included.

The search strategy generated a total of 179 results, among which 46 were RCTs. Two other RCTs were added to this total, taken from the search for full text conference abstracts. The 135 studies eliminated at this stage are detailed in Figure 1. Of the 48 studies available for analysis, only 19 had the primary outcomes of interest. The most common outcomes of the RCTs that have not been included in the analysis were hemodynamic and echocardiography 


\section{Original Article}

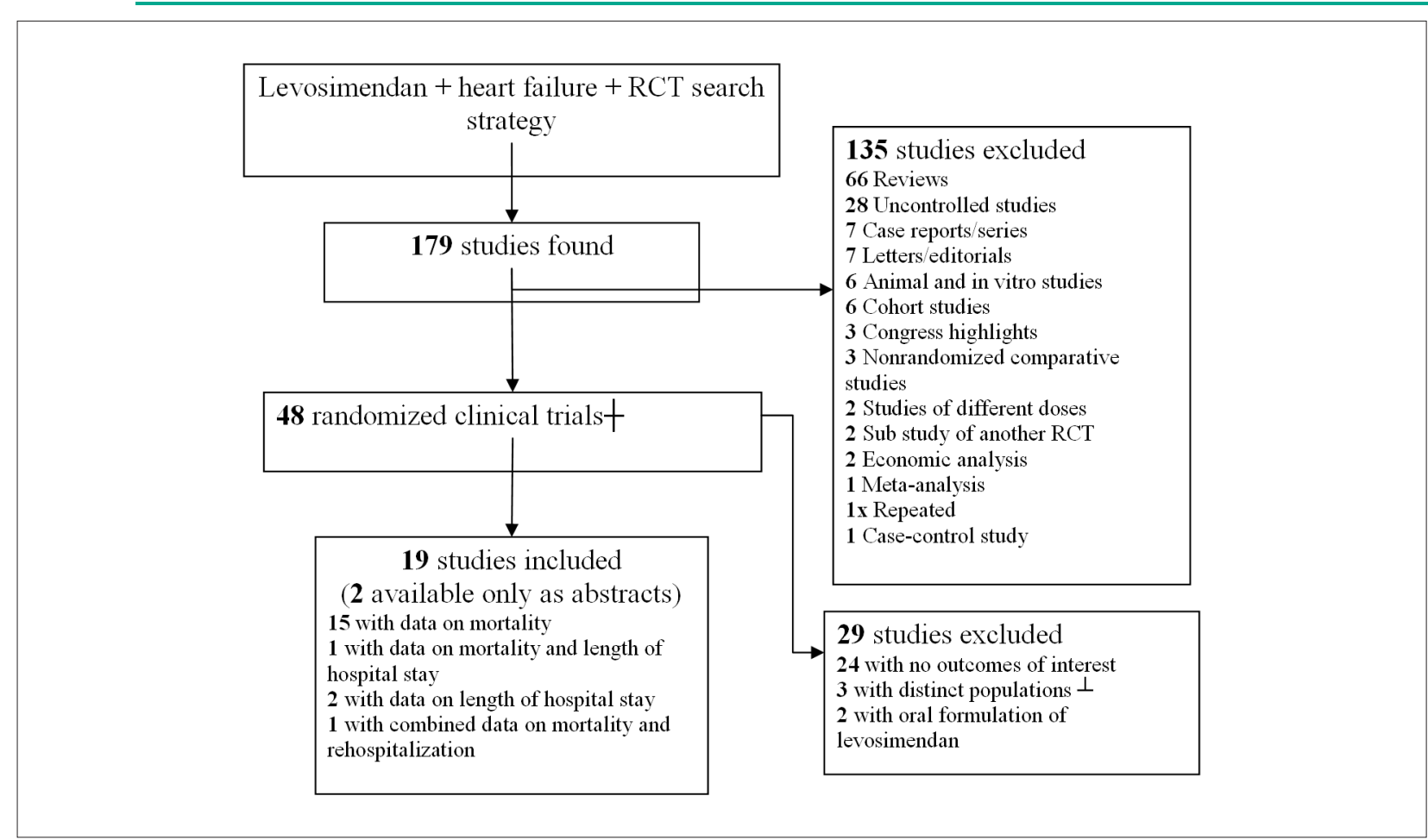

Figure 1 - Search strategy results. +44 clinical trials found among the 179 search results, 2 clinical trials from congress highlights, and 2 studies found in a metaanalysis. $\perp$ Two studies evaluated the drug in patients with heart failure in outpatient treatment, with repeated doses over time; and the third one evaluated levosimendan in patients with septic shock.

parameters; changes in inflammatory markers and B-type natriuretic peptide (brain natriuretic peptide, BNP); and symptom changes in 48 hours.

The most common primary outcome of the studies included in the review was mortality, which was reported in 15 of 19 individual studies and was aggregated to the hospital readmission outcome in another study. The followup for death evaluation ranged from 9 to 365 days (Tables 1 and 2). Only one study reported rates of rehospitalization individually and three studies reported length of stay. As the study conducted by Parissi et al ${ }^{11}$ did not provide separate data for mortality and length of stay, and as there was no other study in which this data were presented on an aggregated form, the Parissi study was not included in our meta-analysis calculations.

Of the 16 studies available for evaluation of mortality, 4 had a comparison only with placebo; 9 had a comparison with another active drug - dobutamine in 7 studies, enoximone in 1 study, and prostaglandin E1 in the remaining study - and three studies conducted both comparisons with placebo and with an active drug (dobutamine in all cases). As the study by Berger et al was the only one that used prostaglandin E1 $1^{12}$ as a comparative drug, and the study of Fuhrmann ${ }^{13}$ was the only one to use enoximone, both were also excluded from metaanalysis calculations. Therefore, the calculations were done with data from 7 studies in which a comparison with placebo was conducted, and 10 studies in which a comparison with dobutamine was conducted.

\section{Levosimendan versus placebo}

\section{Outcome: death}

The characteristics of the studies included in the review are listed in Table 1.

In the primary analysis, which included all the studies and in which the random effects method was used, the relative risk was $0.87(95 \% \mathrm{Cl}: 0.65$ to 1.18$)$, and no significant benefit with the use of levosimendan was observed, when compared with placebo (Figure 2). This result remained consistent on the sensitivity analysis, regardless of changing both the measure of association (for odds ratio) and the method of calculation (fixed effects); the narrowest confidence interval among the 4 tests was the fixed effect for relative risk of death (RR $0.90,95 \% \mathrm{Cl}$ : 0.71 to 1.15$)$.

The other planned sensitivity analyses were hampered by the poor quality of reporting in those studies. It was not possible to conduct a sensitivity analysis excluding studies with absence or lack of clarity regarding the allocation concealment, as all studies were eliminated in this analysis. Nor was it possible to combine the results of studies that presented sample size calculation, as only one study fulfilled this criterion. The results are robust when only studies by intention to treat were included ( 2 studies, $\mathrm{n}=620, \mathrm{RR}=$ $0.72,95 \% \mathrm{Cl}:=0.51$ to 1.01$)$. In the analysis that included only studies with blinding ( 3 studies, $\mathrm{n}=766$ ), the RR was 0.70 (95\% Cl: 0.50 to 0.98$)$.

With the inclusion of unpublished data from a 6-month 
Table 1 - Methodological characteristics of studies on levosimendan versus placebo

\begin{tabular}{|c|c|c|c|c|c|c|c|c|c|}
\hline \multirow[b]{2}{*}{ Study } & \multicolumn{3}{|c|}{ Levosimendan group } & \multirow{2}{*}{$\begin{array}{c}\text { Placebo } \\
\text { group }\end{array}$} & \multirow{2}{*}{$\begin{array}{l}\text { Follow-up } \\
\text { period } \\
\text { (days) }\end{array}$} & \multicolumn{4}{|c|}{ Methodological quality } \\
\hline & $\begin{array}{l}\text { Loading } \\
\text { dose } \\
(\mu \mathrm{g} / \mathrm{kg})\end{array}$ & $\begin{array}{l}\text { Maintenance } \\
\text { dose }(\mu \mathrm{g} / \mathrm{kg} / \\
\mathrm{min})\end{array}$ & $\begin{array}{l}\text { Deaths/ } \\
\text { Total } \\
\text { patients }\end{array}$ & & & $\begin{array}{l}\text { Allocation } \\
\text { concealment }\end{array}$ & $\begin{array}{c}\text { Sample } \\
\text { size } \\
\text { calculation }\end{array}$ & $\begin{array}{l}\text { Intention } \\
\text { to treat } \\
\text { analysis }\end{array}$ & Blinding \\
\hline Nieminen ${ }^{21}, 2000$ & 3 a 36 & 0.05 a 0.6 & $1 / 95$ & $0 / 21$ & 9 & No/Not clear & Yes & Yes & Yes \\
\hline $\begin{array}{l}\text { RUSSLAN }{ }^{22} \\
2002\end{array}$ & 6 a 24 & 0.1 a 0.4 & $91 / 402$ & $32 / 102$ & 180 & No/Not clear & No & Yes & Yes \\
\hline Kivikko ${ }^{23}, 2003$ & 6 & 0.1 a 0.4 & $2 / 98$ & $3 / 48$ & 14 & No/Not clear & No & No & Yes \\
\hline $\mathrm{CASINO}^{24}, 2004$ & NR & NR & $6 / 98^{*}$ & $8 / 97^{*}$ & 30 & No/Not clear & No & No & No/Not clear \\
\hline REVIVE $\|^{20}, 2005$ & 12 & 0.1 a 0.2 & $45 / 299$ & $35 / 301$ & 90 & No/Not clear & No & No & No/Not clear \\
\hline $\begin{array}{l}\text { Adamopoulos }{ }^{25} \\
2006\end{array}$ & 6 & 0.1 & $2 / 23$ & $4 / 23$ & 120 & No/Not clear & No & No & No/Not clear \\
\hline Parissis $^{14}, 2007$ & 0 & 0.1 & $\mathrm{NR} / 42$ & $\mathrm{NR} / 21$ & NR & No/Not clear & No & No & No/Not clear \\
\hline
\end{tabular}

* Outcomes at one month follow-up, full 6-month unpublished data have been considered in sensitivity analysis. NR - not reported.

Table 2 - Methodological characteristics of studies on levosimendan versus dobutamine

\begin{tabular}{|c|c|c|c|c|c|c|c|c|c|}
\hline \multirow[b]{2}{*}{ Study } & \multicolumn{3}{|c|}{ Levosimendan group } & \multirow{2}{*}{$\begin{array}{c}\begin{array}{c}\text { Dobutamine } \\
\text { group }\end{array} \\
\begin{array}{c}\text { Deaths/total } \\
\text { patients }\end{array}\end{array}$} & \multirow{2}{*}{$\begin{array}{l}\text { Follow-up } \\
\text { period } \\
\text { (days) }\end{array}$} & \multicolumn{4}{|c|}{ Methodological quality } \\
\hline & $\begin{array}{l}\text { Loading } \\
\text { dose } \\
(\mu \mathrm{g} / \mathrm{kg})\end{array}$ & $\begin{array}{c}\text { Maintenance } \\
\text { dose }(\mu \mathrm{g} / \mathrm{kg} / \\
\mathrm{min})\end{array}$ & $\begin{array}{l}\text { Deaths/ } \\
\text { total } \\
\text { patients }\end{array}$ & & & $\begin{array}{l}\text { Allocation } \\
\text { concealment }\end{array}$ & $\begin{array}{c}\text { Sample } \\
\text { size } \\
\text { calculation }\end{array}$ & $\begin{array}{l}\text { Intention } \\
\text { to treat } \\
\text { analysis }\end{array}$ & Blinding \\
\hline Follath ${ }^{27}, 1999$ & 12 & 0.2 a 0.6 & $3 / 9$ & $3 / 10$ & 14 & No/Not clear & No & Yes & $\begin{array}{l}\text { No/Not } \\
\text { clear }\end{array}$ \\
\hline $\begin{array}{l}\text { Nieminen }{ }^{21}, \\
2000\end{array}$ & 3 a 36 & 0.05 a 0.6 & $1 / 95$ & $1 / 20$ & 9 & No/Not clear & Yes & Yes & Yes \\
\hline LIDO ${ }^{15}, 2002$ & 24 & 0.1 a 0.2 & $27 / 103$ & $38 / 100$ & 180 & Yes & Yes & Yes & Yes \\
\hline $\mathrm{CASINO}^{24}, 2004$ & NR & NR & $6 / 98^{*}$ & $12 / 96^{*}$ & 30 & No/Not clear & No & No & $\begin{array}{l}\text { No/Not } \\
\text { clear }\end{array}$ \\
\hline $\begin{array}{l}\text { Adamopoulos } 25 \\
2006\end{array}$ & 6 & 0.1 & $2 / 23$ & $5 / 23$ & 120 & No/Not clear & No & No & $\begin{array}{l}\text { No/Not } \\
\text { clear }\end{array}$ \\
\hline Álvarez ${ }^{28}, 2006$ & 12 & 0.2 & $1 / 21$ & $1 / 20$ & 15 & No/Not clear & Yes & No & $\begin{array}{l}\text { No/Not } \\
\text { clear }\end{array}$ \\
\hline $\begin{array}{l}\text { SURVIVE }{ }^{29} \\
2007\end{array}$ & 12 & 0.1 a 0.2 & $173 / 664$ & $185 / 663$ & 180 & Yes & Yes & Yes & Yes \\
\hline $\begin{array}{l}\text { Samimi-Fard }{ }^{30} \\
2008\end{array}$ & 24 & 0.1 & $3 / 11$ & $1 / 11$ & 365 & No/Not clear & No & Yes & No \\
\hline Duygu $^{31}, 2008$ & 6 a 12 & 0.1 & $2 / 30$ & $1 / 30$ & NR & No/Not clear & No & Yes & No \\
\hline $\begin{array}{l}\text { Duygu }(2)^{32} \\
2008\end{array}$ & 6 a 12 & 0.1 & $1 / 20$ & $2 / 20$ & NR & No/Not clear & No & Yes & No \\
\hline Yilmaz $^{16}, 2009$ & NR & 0.1 a 0.2 & $\mathrm{NR} / 17$ & $N R / 13$ & NR & No/Not clear & No & Yes & No \\
\hline
\end{tabular}

* Outcomes at one month follow-up, full 6-month unpublished data have been considered in sensitivity analysis.

follow-up of the CASINO study, provided by the laboratory which sponsored the study, with 17 deaths in the levosimendan group and 27 in the placebo group, no change was shown in the combined estimate with RR calculation by random effects model for death equals to $0.82(95 \% \mathrm{Cl}$ : 0.59 to 1.12 ).

\section{Other outcomes}

In Parissis ${ }^{11}$ study, with 34 patients randomized to levosimendan and placebo, the combination of death and hospital readmission in 5 months occurred in $89 \%$ of patients in the placebo group and $71 \%$ of patients in the levosimendan group $(\mathrm{RR}=1.25,95 \% \mathrm{Cl}: 0.87$ to 1.77$)$. There were no 


\section{Original Article}

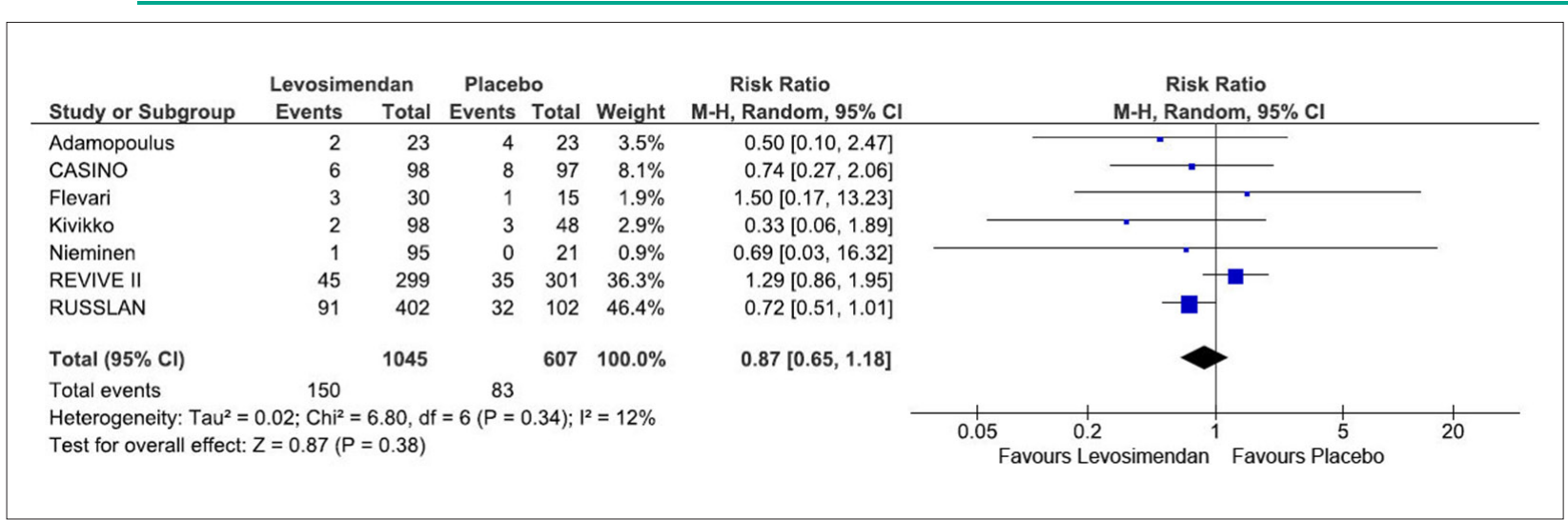

Figure 2 - Meta-analysis of levosimendan versus placebo for the outcome of death, with inclusion of all studies.

results to be combined with these values, due to the absence of other studies with data on readmission ${ }^{13}$.

Data from the REVIVE II study showed a reduction in hospital stay of $7.0 \pm 4.6$ days vs $8.9 \pm 8.6$ days $(p=$ 0.003 ) in favor of levosimendan. In a study by Parissis ${ }^{14}$, levosimendan compared with placebo decreased the length of stay from $5.8 \pm 2.1$ to $3.2 \pm 1.7$ days $(p<0.01)$ in a sample of 63 patients. The aggregate result of these two studies, compiled by meta-analysis for continuous outcomes (weighted mean difference, with random effects), shows a reduction of 2.27 days (95\% Cl: 1.52 to 3.03) in favor of levosimendan in an $\mathrm{N}$ of 663.

\section{Levosimendan versus dobutamine}

\section{Outcome: death}

The characteristics of the studies included in the comparison of levosimendan versus dobutamine are listed in Table 2.

In the primary analysis, in which all studies were included and the method used was the random effects model, the relative risk was 0.87 (95\% $\mathrm{Cl} 0.75$ to 1.02) (Figure 3). When the calculations used for relative risk were done by the fixed effects method, the results remained virtually unchanged $(R R=0.87,95 \% \mathrm{Cl}: 0.74$ to 1.02$)$. When we altered the measure of association to odds ratios, the confidence interval was not statistically significant, regardless of the method of calculation.

In the sensitivity analysis, taking into account the methodological characteristics of the studies, the results remained robust. Evaluating only studies with allocation concealment, the RR was 0.85 (95\% $\mathrm{Cl}: 0.68$ to 1.07$)$, with identical results when we evaluated only blinded studies. In studies with sample size calculation, the RR was 0.85 (95\% Cl: 0.68 to 1.06$)$, and finally, in the analysis by ITT, the RR was 0.87 (95\% Cl: 0.70 to 1.08). Secondary analyses using 6-month data of the CASINO study (41 deaths in the dobutamine group) showed a RR for death, calculated by the method of random effects, of $0.76(95 \% \mathrm{Cl} 0.62$ to 0.93 ) in favor of levosimendan. In all the analyses conducted for mortality, both in comparison with placebo and with dobutamine, the test of inconsistency was lower than 25\% (the maximum value was $13 \%$ ).

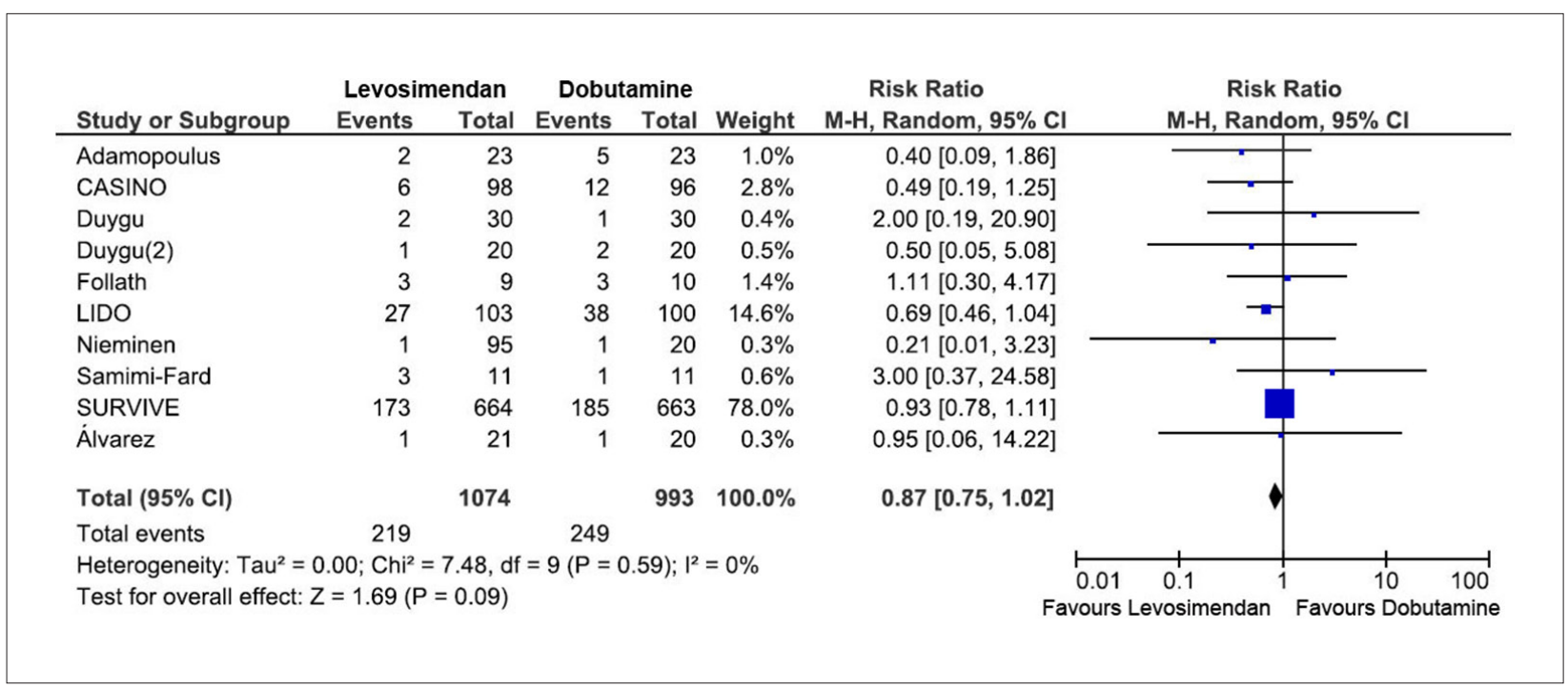

Figure 3 - Meta-analysis of levosimendan versus dobutamine for the outcome of death, with inclusion of all studies. 


\section{Other outcomes}

LIDO $^{15}$ study data showed that the rate of rehospitalization for heart failure, the number, and days of hospitalization for heart failure within 180 days of follow-up were similar in the groups assigned to levosimendan and dobutamine. In the study by Yilmaz, the length of hospital stay was longer in the dobutamine group than in patients who received levosimendan $(11.3 \pm 3.1 \text { versus } 9 \pm 1.8 \text { days, } p=0.024)^{16}$.

\section{Adverse effects}

The most frequently reported adverse effects were hypotension, headache, and arrhythmias. As these patients have a higher risk of sudden death from arrhythmia, this outcome was monitored when inotropic agents were used. There is evidence of an increased incidence of atrial fibrillation and ventricular tachycardia with the use of levosimendan. In the REVIVE study, there was more hypotension (50\% vs $36 \%$ ), ventricular tachycardia (25\% vs $17 \%$ ), and atrial fibrillation ( $8 \%$ vs $2 \%$ ) with levosimendan when compared with placebo. In the SURVIVE study, atrial fibrillation and ventricular premature beats were more frequent with levosimendan, when compared to dobutamine (9.1\% vs $6.1 \%)$, but no difference in the incidence of ventricular tachycardia or fibrillation was observed.

\section{Discussion}

In the management of decompensated heart failure, in its different forms of presentation, the optimal strategy is still widely discussed and controversial. Although levosimendan is used in clinical practice in several countries as an alternative drug in the management of $\mathrm{CHF}$, randomized clinical trials comparing it with placebo are needed to assess the actual safety and benefit of this drug. The results of this meta-analysis demonstrated the absence of consistent evidence of the superiority of levosimendan, when compared with placebo, in reducing mortality of patients admitted for decompensated heart failure. This finding is based on a compilation of 7 clinical trials involving 1,652 patients, and these results were robust when reevaluated in different sensitivity analysis.

When compared with dobutamine for the same outcome, no benefit associated with levosimendan was observed. This finding is based on a compilation of 10 clinical trials involving 2,067 patients, and the results were robust when reevaluated in different sensitivity analyses. The results of both tests are similar to a previous systematic review published at the time, which included basically the same studies included in this review.

In the analysis of other primary outcomes targeted in this systematic review, we found no data on hospital readmission rate. Also, few studies evaluated the length of hospital stay. The only study comparing levosimendan with dobutamine had only 30 patients, and a reliable result was not obtained, although the decrease in length of stay had a statistical significance. When levosimendan was compared with placebo, the data were more consistent, showing a reduction of small magnitude (about two days).

The use of inotropic agents is controversial in the management of $\mathrm{CHF}^{2}$. There seems to be a consensus that high doses of intravenous vasodilators and diuretics represent the first line in cases of acute decompensation, and the use of inotropic agents is relegated to refractory cases. Dobutamine has certainly been the most widely used drug in such situations, although the evidence on the increase of arrhythmias and adverse events has limited its routine use. In recent years, several drugs with inotropic action were tested without much success. Levosimendan is among these newer drugs and has been commonly used in Brazil and in European countries ${ }^{17,18}$.

Data presented in this meta-analysis and in some records, including the Brazilian experience, suggest that some patients may show improvement in dyspnea, in the hemodynamic profile, and in BNP levels with acute infusion of levosimendan ${ }^{17}$. However, such information have intrinsic methodological limitations (studies without blinding, short evaluation period, as well as the subjectivity inherent in the evaluation of dyspnea), which do not permit an objective assessment of whether this drug actually changes the natural history of decompensated heart failure cases.

Moreover, it is increasingly important to consider the cost of therapeutic alternatives, especially in cases like this, in which there is no evidence indicating superiority of one drug over another. The cost of levosimendan is approximately $\mathrm{R} \$$ 4,000.00 per treatment, whereas dobutamine is around $R \$$ 50.00. Although a previous study suggested that the higher cost of levosimendan might be offset by savings resulting from a shorter hospital stay that this drug may entail ${ }^{19}$, the treatment protocols that generated the costs assessed in that study do not seem comparable and, therefore, their data need to be viewed with caution.

It seems clear that this is a population of patients with very serious conditions, in which the benefit of new interventions has been limited or difficult to demonstrate. Acute decompensated heart failure requiring inotropic agents is a terminal condition, in which the main concern is provinding relief of symptoms and maintaining quality of life outside the hospital. Despite the potential deleterious effects, some experts advocate the use of inotropic agents. Indeed, dobutamine has been the option most often used in Brazil in recent decades, with an expected effect on short-term improvement of symptoms, though there is concern about an increased risk of death. Studies comparing levosimendan with dobutamine suggest that the new drug may be an alternative in this scenario, but with no sure benefit.

There are still many doubts about the best clinical strategy for the use of levosimendan in respect to the best fixed or customized dose, the optimal infusion time, whether a loading dose should be used, time of suspension, and the impact of concomitant therapies such as beta blockers, other inotropic agents, or vasodilators. Studies clarifying these facts are needed and can alter the available evidence.

As with any systematic review, some methodological considerations must be recognized. This study is a summation of individual RCT results and reflects the quality of the studies selected. In this sense, we should stress the low methodological quality of these studies, most of them with no sample size calculation and no description of randomization or blinding confidentiality in the analysis of outcomes. 


\section{Original Article}

Moreover, an important study, the CASINO20 study, was presented at a conference some years ago, but has not yet been published in full.

To date, there are no randomized studies showing a reduction in mortality associated with any positive inotropic agent. In this line, the data on levosimendan corroborate the findings that this class of drugs has no effect on overall mortality, cardiovascular mortality, length of stay, or readmission rates for heart failure in hospitalized patients with clinical decompensation. The inclusion of this additional therapy in the therapeutic armamentarium in CHF should be carefully reviewed, and the expected clinical benefit and cost to patients and the health care system.

\section{References}

1. Ministério da Saúde. DATASUS. [Acessado em 02/05/2007]. Disponível em: http://w3.datasus.gov.br/datasus/datasus.php.

2. Bocchi EA, Vilas-Boas F, Perrone S, Caamano AG, Clausell N, Moreira M da C, et al. I Latin American guidelines for the assessment and management of decompensated heart failure. Arq Bras Cardiol. 2005; 85 (Suppl 3): 49-94; 1-48.

3. Cuffe MS, Califf RM, Adams KF Jr, Benza R, Bourge R, Colucci WS, et al. Short-term intravenous milrinone for acute exacerbation of chronic heart failure: a randomized controlled trial. JAMA. 2002; 287 (12): 1541-7.

4. Bayram M, De Luca L, Massie MB, Gheorghiade M. Reassessment of dobutamine, dopamine, and milrinone in the management of acute heart failure syndromes. Am J Cardiol. 2005; 96 (6A): 47G-58G.

5. Innes CA, Wagstaff AJ. Levosimendan: a review of its use in the management of acute decompensated heart failure. Drugs. 2003; 63 (23): 2651-71.

6. Earl GL, Fitzpatrick JT. Levosimendan: a novel inotropic agent for treatment of acute, decompensated heart failure. Ann Pharmacother. 2005; 39 (11): 1888-96.

7. Robinson KA, Dickersin K. Development of a highly sensitive search strategy for the retrieval of reports of controlled trials using PubMed. Int J Epidemiol. 2002; 31 (1): 150-3.

8. Higgins JP, Thompson SG, Deeks JJ, Altman DG. Measuring inconsistency in meta-analyses. BMJ. 2003; 327 (7414): 557-60.

9. Delaney A, Bradford C, McCaffrey J, Bagshaw SM, Lee R. Levosimendan for the treatment of acute severe heart failure: a meta-analysis of randomised controlled trials. Int J Cardiol. 2008; 138 (3): 281-9..

10. Morelli A, De Castro S, Teboul JL, Singer M, Rocco M, Conti G, et al. Effects of levosimendan on systemic and regional hemodynamics in septic myocardial depression. Intensive Care Med. 2005; 31 (5): 638-44.

11. Parissis JT, Panou F, Farmakis D, Adamopoulos S, Filippatos G, Paraskevaidis I, et al. Effects of levosimendan on markers of left ventricular diastolic function and neurohormonal activation in patients with advanced heart failure. Am J Cardiol. 2005; 96 (3): 423-6.

12. Berger R, Moertl D, Huelsmann M, Bojic A, Ahmadi R, Heissenberger I, et al. Levosimendan and prostaglandin E1 for uptitration of beta-blockade in patients with refractory, advanced chronic heart failure. Eur J Heart Fail. 2007; 9 (2): 202-8.

13. Fuhrmann JT, Schmeisser A, Schulze MR, Wunderlich C, Schoen SP, Rauwolf $\mathrm{T}$, et al. Levosimendan is superior to enoximone in refractory cardiogenic shock complicating acute myocardial infarction. Crit Care Med. 2008; 36 (8): 2257-66.

14. Parissis JT, Papadopoulos C, Nikolaou M, Bistola V, Farmakis D, Paraskevaidis I, et al. Effects of levosimendan on quality of life and emotional stress in advanced heart failure patients. Cardiovasc Drugs Ther. 2007; 21 (4): 263-8.

\section{Potential Conflict of Interest}

No potential conflict of interest relevant to this article was reported.

\section{Sources of Funding}

This study was funded by Secretaria de Atenção à Saúde Ministério da Saúde.

\section{Study Association}

This study is not associated with any post-graduation program.
15. Follath F, Cleland JG, Just H, Papp JG, Scholz H, Peuhkurinen K, et al. Efficacy and safety of intravenous levosimendan compared with dobutamine in severe low-output heart failure (the LIDO study): a randomised double-blind trial. Lancet. 2002; 360 (9328): 196-202.

16. Yilmaz MB, Yontar C, Erdem A, Karadas F, Yalta K, Turgut OO, et al. Comparative effects of levosimendan and dobutamine on right ventricular function in patients with biventricular heart failure. Heart Vessels. 2009; 24 (1): 16-21.

17. Bocchi EA, Vilas-Boas F, Moreira MC, Barretto AC, Lage S, Albuquerque D, et al. Levosimendan in decompensated heart failure patients: efficacy in a Brazilian cohort. Results of the BELIEF study. Arq Bras Cardiol. 2008; 90 (3): 182-90.

18. Nieminen MS, Brutsaert D, Dickstein K, Drexler H, Follath F, Harjola VP, et al. EuroHeart Failure Survey II (EHFS II): a survey on hospitalized acute heart failure patients: description of population. Eur Heart J. 2006; 27 (22): 2725-36.

19. Oliveira MT Jr, Follador W, Martins ML, Canaviera R, Tsuji RL, Scipioni A, et al. Cost analysis of the treatment of acute decompensated heart failure. Levosimendan versus dobutamine. Arq Bras Cardiol. 2005; 85 (1): 9-14.

20. Cleland JG, Freemantle N, Coletta AP, Clark AL. Clinical trials update from the American Heart Association: REPAIR-AMI, ASTAMI, JELIS, MEGA, REVIVE-II, SURVIVE, and PROACTIVE. Eur J Heart Fail. 2006; 8 (1): 105-10.

21. Nieminen MS, Akkila J, Hasenfuss G, Kleber FX, Lehtonen LA, Mitrovic V, et al. Hemodynamic and neurohumoral effects of continuous infusion of levosimendan in patients with congestive heart failure. J Am Coll Cardiol. 2000; 36 (6): 1903-12.

22. Moiseyev VS, Poder P, Andrejevs N, Ruda MY, Golikov AP, Lazebnik LB, et al. Safety and efficacy of a novel calcium sensitizer, levosimendan, in patients with left ventricular failure due to an acute myocardial infarction: a randomized, placebo-controlled, double-blind study (RUSSLAN). Eur Heart J. 2002; 23 (18): 1422-32.

23. Kivikko M, Lehtonen L, Colucci WS. Sustained hemodynamic effects of intravenous levosimendan. Circulation. 2003; 107 (1): 81-6.

24. Cleland JG, Ghosh J, Freemantle N, Kaye GC, Nasir M, Clark AL, et al. Clinical trials update and cumulative meta-analyses from the American College of Cardiology: WATCH, SCD-HeFT, DINAMIT, CASINO, INSPIRE, STRATUSUS, RIO-Lipids and cardiac resynchronisation therapy in heart failure. Eur J Heart Fail. 2004; 6 (4): 501-8.

25. Adamopoulos S, Parissis JT, Iliodromitis EK, Paraskevaidis I, Tsiapras D, Farmakis D, et al. Effects of levosimendan versus dobutamine on inflammatory and apoptotic pathways in acutely decompensated chronic heart failure. Am J Cardiol. 2006; 98 (1): 102-6.

26. Flevari P, Parissis JT, Leftheriotis D, Panou F, Kourea K, Kremastinos DT. Effect of levosimendan on ventricular arrhythmias and prognostic autonomic indexes in patients with decompensated advanced heart failure secondary to ischemic or dilated cardiomyopathy. Am J Cardiol. 2006; 98 (12): 1641-5. 
27. Follath F, Hinkka S, Jäger D, Just H, Mitrovic V, Papp J, et al. Dose-ranging and safety with intravenous levosimendan in low-output heart failure: experience in three pilot studies and outline of the levosimendan infusion versus dobutamine (LIDO) trial. Am J Cardiol. 1999; 83 (12B): 16(I)-20(I).

28. Alvarez J, Bouzada M, Fernandez AL, Caruezo V, Taboada M, Rodriguez J, et al. Hemodynamic effects of levosimendan compared with dobutamine in patients with low cardiac output after cardiac surgery. Rev Esp Cardiol. 2006; 59 (4): 338-45.

29. Mebazaa A, Nieminen MS, Packer M, Cohen-Solal A, Kleber FX, Pocock SJ, et al. Levosimendan vs dobutamine for patients with acute decompensated heart failure: the SURVIVE Randomized Trial. JAMA.
2007; 297 (17): 1883-91.

30. Samimi-Fard S, Garcia-Gonzalez MJ, Dominguez-Rodriguez A, AbreuGonzalez P. Effects of levosimendan versus dobutamine on long-term surviva of patients with cardiogenic shock after primary coronary angioplasty. Int Cardiol. 2008; 127 (2): 284-7.

31. Duygu H, Nalbantgil S, Ozerkan F, Zoghi M, Akilli A, Erturk U, et al. Effects of levosimendan on left atrial functions in patients with ischemic heart failure. Clin Cardiol. 2008; 31 (12): 607-13.

32. Duygu H, Turk U, Ozdogan O, Akyuz S, Kirilmaz B, Alioglu E, et al. Levosimendan versus dobutamine in heart failure patients treated chronically with carvedilol. Cardiovasc Ther. 2008: 26 (3): 182-8. 